\title{
Tertiary Trisomics in Pea (Pisum sativum)
}

\author{
V. C. Mercykutty and H. Kumar \\ Department of Genetics and Plant Breeding, Institute of Agricultural Sciences, \\ Banaras Hindu University, Varanasi-221005, India
}

Accepted June 24, 1984

Tertiary trisomics have been reported in a wide range of plants, such as, corn, barley, tomato and rye etc. and have been also effectively used, among others, in hybrid seed production in a few crops (Khush and Rick 1967, Ramage 1965, and others). Remarkably, only a few preliminary reports on tertiary trisomy in pea are available (Müller 1975, Sutton 1939). The present communication deals with the isolation and cytomorphological characterisation of five tertiary trisomics.

\section{Materials and methods}

Seeds of pea (Pisum sativum) of different interchange heterozygotes were raised in $\mathbf{M}_{3}$ generation. Initially these interchanges were induced through $10 \mathrm{KR}$ gammairradiation of the $F_{1}$ seeds originating from a $9 \times 9$ diallel cross involving diverse parents. The off-type plants were marked and subjected to chromosome study at MI and AI. For cytological study, PMCs were collected in acetic-alcohol (1:3) and squeezed in a drop of $2 \%$ aceto-carmine. Pollen sterility was studied by using $2 \%$ iodine-potassium iodide solution.

\section{Results}

The frequency of tertiary trisomics, among other aneuploids, was $0.21 \%$ (5 plants out of 2492 seeds sown). They were present in populations arising from the crosses T163 $\times 5806-\mathrm{S}(2,0.975 \%), \mathrm{T} 163 \times \mathrm{DA}(2,0.362 \%)$ and $46 \mathrm{C} \times \mathrm{PI} 280064(1$, $0.333 \%$, while remaining crosses derived from a $9 \times 9$ diallel set did not yield any tertiary trisomic.

Five tertiary trisomics, distinguishable from their corresponding siblings, were morphologically characterised in the following four groups (Figs. 1-4).

1. L332-2 (T163 $\times 5806-\mathrm{S}-2-2-2-2)$ : This mutant was dwarf with slender stem, small stipule and leaflets. The distance between stipule and first leaflet was highly enlarged. It flowered late by 12 days.

2. i. L284-1 (T163 $\times 5806-\mathrm{S}-1-14-5-1)$ :

ii. L324-3 (T163 $\times$ DA-2-12-2-3):

Both the trisomics had succulent stem with round stipule and leaflets.

3. L307-1 (T163 $\times$ DA-1-5-3-1): It had succulent stem with highly enlarged internode. Stipule and leaflets were small, round and greenish dark in colour. The distance between stipule and 1st leaflet was enlarged. Flowering was late by 19 days. 
4. L350-1 (PI280064 $\times 46 \mathrm{C}-1-1-1-1)$ : This plant was semidwarf and slender stem with small and erect stipule and leaflets.

Chromosome configurations at $\mathrm{MI}$ and $\mathrm{AI}$ in tertiary trisomics are given in Figs. 5-8 and Table 1 . On an avergae, the tertiary trisomics showed $38.4 \%$ cells
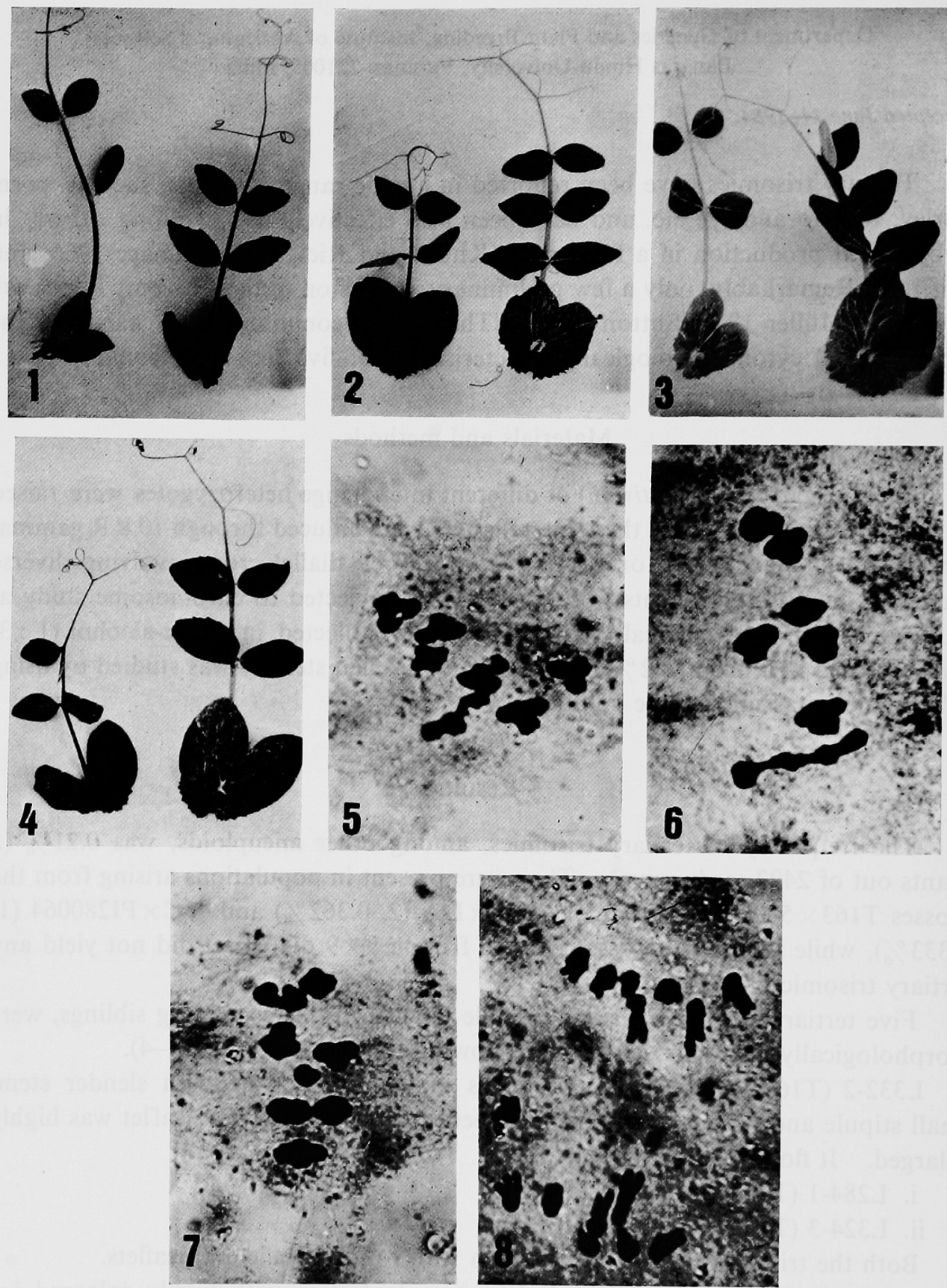

Figs. 1-8. 1-4: Leaves of four tertiary trisomics (left) and their corresponding control (rright) of pea. 1, L332-2. 2, L284-1. 3, L307-1. 4, L350-1. 5-8: Chromosome configuration in tertiary trisomics of pea. 5, metaphase I, $1 \mathrm{~V}+5 \mathrm{II}$. 6, metaphase I, 1III+6II. 7, metaphase I, 7II +1I. 8, anaphase I, 8: 7 disjunction. 
with pentavalent ranging from 32.0 (L284-1 and L350-1) to 48.0 (L324-3) per cent. The modal configuration was $1 \mathrm{III}+6 \mathrm{II}(50.0 \%$ cells $)$. At AI, 8-7 distribution was in excess $(66.7 \%)$ ranging from 53.3 (L307-1) to 80.0 (L284-1) per cent cells. Only $17.8 \%$ cells showed laggards.

Tertiary trisomics accounted about 45.0 per cent pollen fertility ranging from 30.4 (L350-1) to 67.0 (L324-3) per cent. Seed fertility was very poor. Seed yield ranged from nil to 4 seeds per plant; two trisomics (L332-2 and L350-1) failed to produce any seed.

\section{Discussion}

Trisomics occur in the progeny of interchange heterozygote as a result of $3: 1$ disjunction of the configuration of 4 chromosomes at AI resulting in the formation of $n+1$ gametes (Burnham 1962, Ramage 1960; and others). The $n+1$ gametes having two normal chromosomes plus one extra interchanged chromosome upon fertilization with $\mathrm{n}$ pollen produce tertiary trisomic.

Tertiary trisomics showed wide range of variations in morphophysiological traits as compared to diploid sibs, which indicated that each of the four types of tertiary trisomics probably had different extra chromosome.

Although, size and shape of stipules and leaflets were appeared to be characteristic feature, none of the characters was found to be quite effective in distinguishing between the different types of tertiary trisomics.

The frequencies of the different associations at MI, obviously depend upon the length of the chromosomes involved, the duplicated segments and the chiasma frequency. The distinguishing configuration in tertiary trisomic is a pentavalent. Data presented in Table 1 clearly inicated the high frequencies of cells with $1 \mathrm{~V}+5 \mathrm{II}$ $(38.4 \%)$ and $1 \mathrm{III}+6 \mathrm{II}(50.0 \%)$ configurations in tertiary trisomics as also observed in tomato (Khush and Rick 1967). In general, the extra chromosomes with two long arms tended to form pentavalent at higher frequency than the ones with two short arms, while those which one long and one short arm tended to have intermediate frequencies (Khush 1973).

Fertility of tertiary trisomics, as judged in terms of seed production, was very poor eventhough they displayed pollen fertility ranging from 34.6 to $67.0 \%$. The high or complete sterility of trisomics was ascribed to imbalance between aneuploid and euploid cells, in addition to trisomy and interchange heterozygosity (Das and Srivastava 1969). Thus, the seed sterility in the tertiary trisomy was evidently due to the presence of an extra chromosome. It might be also noted that none of the parental interchanges analysed in this laboratory (Kumar, personal communication) showed such a high seed sterility. Since tertiary trisomics did not produce adequate seeds, further studies on them could not be undertaken.

\section{Summary}

Five tertiary trisomics, isolated in the progenies of interchange heterozygotes, were morphologically classified into four groups. They might be named as slender, 


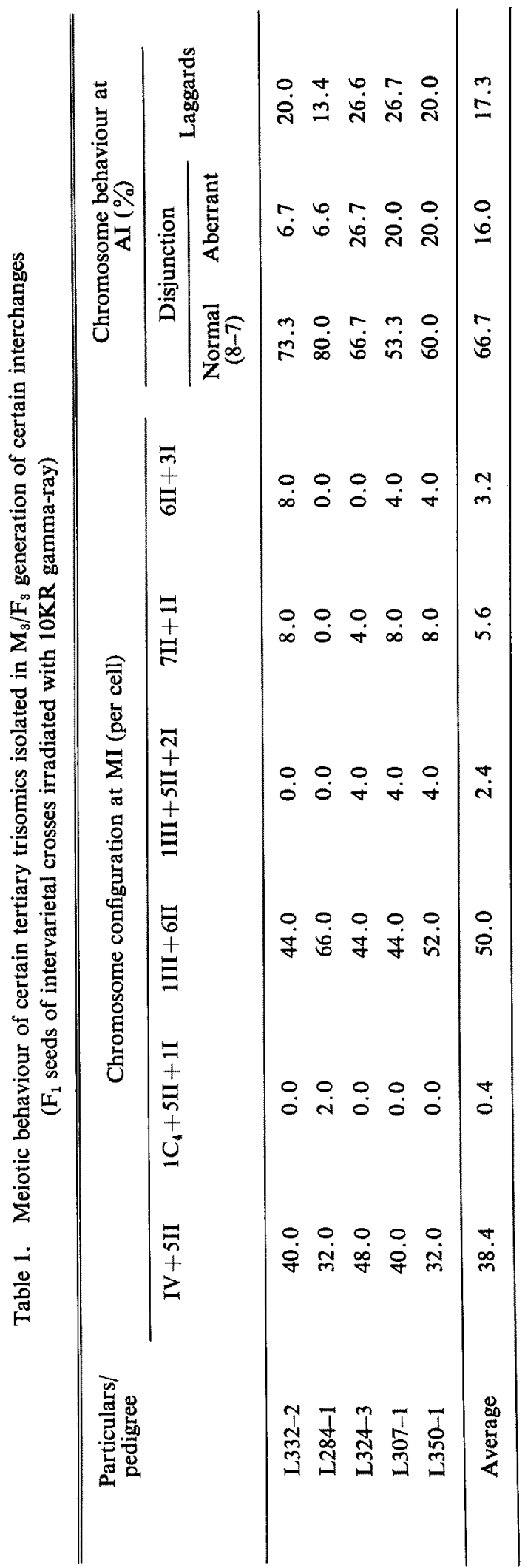


succulent, enlarged internode and small-erect stipule, respectively. At MI, characteristic pentavalent configuration was accounted in $38.4 \%$ cells; the modal configuration was $1 \mathrm{III}+6 \mathrm{II}(50.0 \%)$. At AI, 7-8 disjunction was about $66.7 \%$. Pollen fertility ranged from 304 to $67.0 \%$, while seed yield was very poor, ranging from $0-4$ seeds per plant.

\section{Acknowledgement}

Financial assistance of C.S.I.R., New Delhi to first author is acknowledged.

\section{References}

Burnham, C. R. 1962. Discussions in Cytogenetics. Burgess Publ. Co., Minnesota, U.S.A. Das, K. and Srivastava, H. M. 1969. Interchange trisomics in barley. Genetica 40: 555-565. Khush, G. S. 1973. Cytogenetics of Aneuploids. Academic Press. New York.

- and Rick, C. M. 1967. Tomato tertiary trisomics: Origin, identification, morphology and use in determining position of centromere and arm location of markers. Can. J. Genet. Cytol. 9: 610-631.

Müller, D. 1975. Tertiary trisomics for chromosome 35 in Pisum sativum L. Caryologia 28: 111-124.

Ramage, R. T. 1960. Trisomics from interchange heterozygotes in barley. Agron. J. 52: 156159.

- 1965. Balanced tertiary trisomics for use in hybrid seed production. Crop Sci. 5: 177-178.

Sutton, E. 1939. Trisomics in Pisum sativum derived from an interchange heterozygote. J. Genet. 38: $459-477$. 